\title{
Parkinson's disease and Alzheimer's disease: hypersensitivity to $X$ rays in cultured cell lines
}

\author{
JAY H ROBBINS, FUJIO OTSUKA, ROBERT E TARONE, ${ }^{*}$ RONALD J POLINSKY, $\dagger$ \\ ROGER A BRUMBACK, $\ddagger$ LINDA E NEE $\dagger$
}

From the Dermatology and Biostatistics* Branches, National Cancer Institute, Laboratory of Clinical Science, $\dagger$ National Institute of Mental Health, National Institutes of Health, Bethesda, MD, Department of Pathology, $\ddagger$ University of Rochester Medical Center, Rochester, NY, USA

SUMMARY Fibroblast and/or lymphoblastoid lines from patients with several inherited primary neuronal degenerations are hypersensitive to DNA-damaging agents. Therefore, lymphoblastoid? lines were irradiated from patients with sporadic Parkinson's disease (PD), Alzheimer's disease $\overrightarrow{\vec{\omega}}$ and amyotrophic lateral sclerosis. The mean survival values of the eight Parkinson's disease and of the six Alzheimer's disease lines, but not of the five amyotrophic lateral sclerosis lines, were less than that of the 28 normal lines. Our results with Parkinson's disease and Alzheimer's disease cells can be explained by a genetic defect arising as a somatic mutation during embryogenesis ${ }_{i 0}^{\infty}$ causing defective repair of the X-ray type of DNA damage. Such a DNA repair defect coulde cause an abnormal accumulation of spontaneously occurring DNA damage in Parkinson's disease and Alzheimer's disease neurons in vivo, resulting in their premature death.

Recent studes have identified a group of disorders which have hypersensitivity in vitro to DNAdamaging agents and the neuropathological features of a primary neuronal degeneration. ${ }^{\prime}$ Xeroderma pigmentosum is an autosomal recessive disease with inherited defects in mechanisms for repairing DNA damaged by ultraviolet radiation. ${ }^{2}$ Some xeroderma pigmentosum patients have a primary neuronal degeneration involving principally the pyramidal cells of the cerebral cortex, the Purkinje cells of the cerebellum, the deep nuclei of the basal ganglia and cerebellum, the zona compacta of the substantia nigra, and the locus ceruleus. ${ }^{1-5}$ In advanced cases the spinal cord pathology resembles that of Friedreich's ataxia..$^{5}$ The degree of in vitro sensitivity of cultured xeroderma pigmentosum fibroblast and lymphoblastoid cell lines to the lethal effects of ultraviolet radiation correlates with the age of onset and severity of neurological signs in this disease. ${ }^{146-8}$ Because of these findings we proposed that the primary neuronal degeneration in xeroderma pigmentosum results from the in vivo

Address for reprint requests: Dr Jay $\mathbf{H}$ Robbins, Building 10, Room 12N258, National Institutes of Health, Bethesda, MD 20205, USA.

Received 28 December 1984. Accepted 16 February 1985 accumulation in neurons of unrepaired DNA damage. ${ }^{2469-11}$ This DNA-damage hypothesis was $\frac{\mathbb{D}}{3}$ expanded to include other DNA-damaging agents and primary neuronal degenerations. ${ }^{19} 101213$ Co sistent with this hypothesis, hypersensitivity to the $\overrightarrow{0}$ lethal effects of ionising radiation and/or or radiomimetic chemicals has been found in cultured cells from patients with ataxia telangiectasia, ${ }^{12} 14^{-19} \mathrm{O}$ Friedreich's ataxia, ${ }^{20}$ Huntington's disease, $12151621-24$ and familial dysautonomia. ${ }^{24}$ We now report that lymphoblastoid lines from patients with Parkinson's $\frac{0}{\varnothing}$ disease and Alzheimer's disease, but not those from patients with amyotrophic lateral sclerosis, are $\overrightarrow{\bar{O}}$ hypersensitive to $\mathrm{X}$-rays. A preliminary report of 3 some of these findings has been published. ${ }^{13}$

\section{Methods}

Origins of normal and patient lymphoblastoid lines. Lymphoblastoid lines are Epstein-Barr virus-transformed peripheral blood B lymphocytes which grow as immortallines in suspension culture. With the exception of two nor-尺 mal lines, all normal and patient lines were established at $\bar{\gamma}$ the Institute for Medical Research, Camden, NJ. A total ofo 28 normal lymphoblastoid lines were studied from donors who were not known to have any neurological disease $\frac{D}{0}$ Their age and sex, as well as the designation and post- $X-$. ray survival of their cell lines, have been presented previ- $N$ ously. ${ }^{25}$ The mean age at venepuncture for obtaining blood for establishment of the lines from 27 of these donors (the $N$ 
Table 1 Designations, derived lymphoblastoid lines, viability ratios, and clinical features of Parkinson's disease patients

\begin{tabular}{|c|c|c|c|c|c|c|c|c|c|c|c|c|c|c|}
\hline \multirow[t]{2}{*}{ Patient } & \multirow[t]{2}{*}{$A g e^{*}$} & \multirow[t]{2}{*}{$\operatorname{Sex}$} & \multirow{2}{*}{$\begin{array}{l}\text { Cell } \\
\text { line }\end{array}$} & \multirow{2}{*}{$\begin{array}{l}\text { Viability } \\
\text { ratiot }\end{array}$} & \multicolumn{10}{|c|}{ Clinical features } \\
\hline & & & & & $\begin{array}{l}\text { Brady- } \\
\text { kinesia }\end{array}$ & $\begin{array}{l}\text { Rigid- } \\
\text { ity }\end{array}$ & Tremor & Akinesia & $\begin{array}{l}\text { Shuffting } \\
\text { gait }\end{array}$ & $\begin{array}{l}\text { Changed } \\
\text { hand-: } \\
\text { writing }\end{array}$ & $\begin{array}{l}\text { Decreased } \\
\text { eye } \\
\text { blinking }\end{array}$ & $\begin{array}{l}\text { Decreased } \\
\text { facial } \\
\text { expression }\end{array}$ & $\begin{array}{l}\text { Decreased } \\
\text { associated } \\
\text { movements }\end{array}$ & $\begin{array}{l}\text { Response to } \\
\text { anti-Parkin- } \\
\text { s sonian drugs }\end{array}$ \\
\hline $\begin{array}{l}\text { PD1FABE } \\
\text { PD2FABE } \\
\text { PD3FABE } \\
\text { PD4BE } \neq \\
\text { PD5FABE } \\
\text { PD6BE } \\
\text { PD7BE } \\
\text { PD8BE }\end{array}$ & $\begin{array}{l}71 \\
52 \\
60 \\
64 \\
53 \\
64 \\
65 \\
63\end{array}$ & $\begin{array}{l}\mathbf{M} \\
\mathbf{M} \\
\mathbf{M} \\
\mathbf{F} \\
\mathbf{M} \\
\mathbf{M} \\
\mathbf{M} \\
\mathbf{M}\end{array}$ & $\begin{array}{ll}\text { RB } & 3937 \\
\text { RB } & 3971 \\
\text { RB } & 3973 \\
\text { RB } & 4642 \\
\text { RB } & 5288 \\
\text { RB } & 5828 \\
\text { RB } & 5860 \\
\text { RB } & 6041\end{array}$ & $\begin{array}{l}0.43 \\
0.45 \\
0.50 \\
0.43 \\
0.48 \\
0.48 \\
0.45 \\
0.50\end{array}$ & $\begin{array}{l}+ \\
+ \\
+ \\
+ \\
+ \\
+ \\
+\end{array}$ & $\begin{array}{l}+ \\
+ \\
+ \\
+ \\
+ \\
+ \\
+ \\
+\end{array}$ & $\begin{array}{l}+ \\
+ \\
+ \\
+ \\
+ \\
+ \\
+ \\
+\end{array}$ & $\begin{array}{l}+ \\
+\end{array}$ & $\begin{array}{l}+ \\
+ \\
+ \\
+\end{array}$ & $\begin{array}{l}+ \\
+\end{array}$ & $\begin{array}{l}+ \\
+\end{array}$ & $\begin{array}{l}+ \\
+\end{array}$ & + & $\begin{array}{l}+ \\
+ \\
+ \\
+ \\
+ \\
+ \\
+ \\
+\end{array}$ \\
\hline
\end{tabular}

*Age at venepuncture for obtaining blood for establishment of lymphoblastoid lines.

tFor 100 rads of X-rays; each ratio is the mean of at least six replicate experiments and is calculated as described in Materials and Methods. $¥$ Mother had PD.

PD Parkinson's disease. FA Fargo, North Dakota. BE Bethesda, Maryland. + known to be present.

age of one donor was not known) was $44 \cdot 0$ years (range, 12 to 71 years), and their ages represented every decade from the second to the eighth decade of life. The 11 oldest of the 27 normal donors had a mean age of 62.8 years (range, 54 to 71 years). The two lines (E1, R1) established in our laboratory were from donors who had not received any formal clinical evaluation. The 14 normal lines with the GM prefix in their designations were from donors whose blood had been acquired by the NIGMS Human Genetic Mutant Cell Repository at the Institute for Medical Research and are described in the Institute's catalogue of cell lines. Twelve normal donors, who were extensively screened at the National Institutes of Health, comprised the NIH normal donor series, and their cell lines carry the 'RB' prefix in their designations. Each of these 12 donors was required to submit a complete medical history and undergo a physical examination, screening blood tests, urinalysis, electrocardiogram, chest radiography, and a detailed neurological examination conducted by a neurologist (RJP). None had symptoms or signs of any active illness. Extensive family pedigrees spanning several generations were constructed. Subjects were excluded from the NIH normal donor series if there was any family history of neurological disorder.

Lymphoblastoid lines from eight Parkinson's disease patients were studied. The identification and clinical features of these patients are presented in table 1. The Parkinson's disease patients had a mean age of 61.5 years (range, 52 to 71 years). Each patient had a gradual onset of cogwheel rigidity, resting tremor, and/or bradykinesia. Associated symptoms in some patients included shuffling gait, akinetic episodes, change in handwriting, decreased eye blinking, masked facies, and lack of associated movements. All patients showed symptomatic improvement in response to treatment with anti-Parkinsonian medication. Patients with evidence of motor neuron disease, cerebellar signs, dysautonomic syndrome, gaze limitation, profound dementia, or a history of exposure to drugs or toxic substances known to produce Parkinsonism were excluded from this study. Patient PD4BE was considered to have familial Parkinson's disease, since she had a first degree relative (mother) with this disease.

The six Alzheimer's disease patients (table 2) had a mean age of 62.5 years (range, 58 to 69 years). All
Alzheimer's disease patients had cognitive dysfunction which began insidiously before 65 years of age. Progressive intellectual deterioration had been present for at least one year prior to neurological evaluation. No patient had a history of stroke-like episodes or a known disorder associated with central nervous system involvement. Diffuse cerebral atrophy and ventricular dilatation were observed in all Alzheimer's disease patients by computed tomographic scan. After a complete medical and neurological evaluation, no other cause for the dementia was found. One patient (AD1BE) is an index case of an extensive pedigree of histologically confirmed familial Alzheimer's disease. ${ }^{26}$

The five patients with amyotrophic lateral sclerosis (table 2 ) had an inexorably progressive disease characterised by muscle weakness and wasting. They had clinical (fasciculations and atrophy) and electromyographic (fibrillations and large polyphasic motor units) evidence of denervation in muscles of both the upper and lower extremities. Nerve conduction velocity was normal. Upper

Table 2 Designations, derived lymphoblastoid lines, and viability ratios of Alzheimer's disease, multiple sclerosis, and amyotrophic lateral sclerosis patients

\begin{tabular}{lllll}
\hline Patient & $\begin{array}{l}\text { Age } \\
(y r)\end{array}$ & Sex & Cell line & $\begin{array}{l}\text { Viability } \\
\text { ratiot }\end{array}$ \\
\hline AD1BE & 58 & F & RB 4160 & 0.50 \\
AD2BE & 59 & F & RB 4964 & 0.45 \\
AD3BE & 61 & F & RB 5054 & 0.47 \\
AD4BE & 69 & F & RB 5176 & 0.46 \\
AD5BE & 67 & M & AG 6204 & 0.51 \\
AD6BE & 60 & F & AG 6868A & 0.44 \\
MS1FABE & 56 & M & RB 3939 & 0.57 \\
MS2FABE & 52 & M & RB 3975 & 0.52 \\
MS3FABE & 59 & F & RB 4001 & 0.50 \\
MS4FABE & 56 & M & RB 4003 & 0.53 \\
MS5FABE & 31 & M & RB 5362 & 0.53 \\
ALS1FABE & 68 & M & RB 4073 & 0.56 \\
ALS2FABE & 72 & M & RB 4075 & 0.50 \\
ALS3FABE & 40 & F & RB 4532 & 0.55 \\
ALS4FABE & - & M & RB 4607 & 0.62 \\
ALS5FABE & 65 & M & RB 5698 & 0.48 \\
\hline
\end{tabular}

*As in table 1; age of patient ALS4FABE is unknown.

tAs in table 1 .

AD Alzheimer's disease. BE Bethesda, Maryland. MS Multiple sclerosis. FA Fargo, North Dakota. ALS amyotrophic lateral sclerosis. 
motor neuron signs (hyperreflexia and extensor plantar responses) were also present. There were no sensory abnormalities or cerebellar or extrapyramidal signs. The five patients with multiple sclerosis (table 2) were diagnosed on the basis of multiple exacerbating and remitting central nervous system signs and symptoms and fit the diagnostic criteria for clinically definite multiple sclerosis (CDMS A1). ${ }^{27}$

Tissue culture methods, irradiation with $X$-rays, and viability determination. Culturing, irradiation, and viability determination were performed as in previous experiments $^{8121718}$ and as described in detail elsewhere. ${ }^{25}$ For experiments in which only 100 rads of $X$-rays were to be administered, the stock cell suspensions were diluted with fresh culture medium to a final concentration of $2 \times 10^{\text {s }}$ viable cells $/ \mathrm{ml}$. For the dose-response experiments, each line's stock cell suspension was centrifuged at $600 \mathrm{~g}$ just prior to irradiation, and the cells were resuspended at a final concentration of $3 \times 10^{5}$ viable cells/ml of fresh culture medium. The cell lines were irradiated at room temperature at $126 \mathrm{rads} / \mathrm{min}$ with a $235-\mathbf{k V p} \mathrm{X}$-ray machine. Concentrations of viable (that is, trypan-blue dyeexcluding) cells in unirradiated and irradiated cultures were determined on the third postirradiation day using coded samples to eliminate any possibility of observer bias. Ultraviolet irradiation. The experiments were performed as described above except that after centrifugation the cells were resuspended at a final concentration of approximately $4 \times 10^{6}$ viable cells/ml of Hanks' balanced salt solution (without phenol red). Some of the resuspended cells were then irradiated with 254-nm ultraviolet irradiation at a flux of $0.08 \mathrm{~J} / \mathrm{m}^{2}$ from a germicidal lamp (General Electric No G15T8). Immediately after the time of irradiation, each cell suspension was diluted with seven volumes of fresh medium, and the irradiated and unirradiated cells were incubated for three days when the viable cells were determined by the dye-exclusion method.

Computation of viability ratio. A line's postirradiation viability ratio was calculated by dividing the concentration of viable cells in an irradiated culture on the third postirradiation day by the concentration of viable cells in an unirradiated culture of the same line on the third day. Thus, calculation of the viability ratio automatically corrects for differences in unirradiated growth rates among the cell lines, as described in detail previously. ${ }^{825}$ Experiments in which the viable cells in the unirradiated culture had not tripled in concentration by the third day were discarded. There was no correlation between the postirradiation viability ratios of either normal or patient lines and the lines' unirradiated growth ratios or the ages or sexes of the cell donors. The three-day unirradiated growth ratios \pm standard error of the Parkinson's disease $(5.0 \pm 0.4)$ and Alzheimer's disease $(5 \cdot 7 \pm 0.7)$ lines were not significantly different from that $(5.6 \pm 0.3)$ of the normal lines $(p \geqslant$ $0.25)$. Comparisons of disease groups with the normal group are based on the standard $t$ test for comparing independent means, ${ }^{28}$ and two-sided $p$ values are reported. Validation of the survival assay and viability ratio. Ataxia telangiectasia is a recessively inherited primary neuronal degeneration..$^{29}$ As cited and reviewed elsewhere, ${ }^{25}$ several investigators have compared the post-ionizingradiation colony-forming ability of ataxia telangiectasia homozygote and heterozygote fibroblast and lymphoblastoid lines with that of normal lines. The survival of fibroblast lines has ranged from 30 to $45 \%$ of normal for ataxia telangiectasia homozygote lines and from 74 to $90 \%$ of normal for ataxia telangiectasia heterozygote lines. For lymphoblastoid lines the reported values were 36 and $80 \%$, respectively. ${ }^{14}$ The relative survival based on viability ratios currently obtained with our lymphoblastoid line survival assay, $50 \%$ for ataxia telangiectasia homozygote (GM 717, 1526, 3189) and 75\% for ataxia telangiectasia heterozygote (GM 3187, 3188) lines, are in good agreement with these published data based on colony forming ability. The validity of the viability ratio as a measure of cell survival after ultraviolet irradiation treatment of xeroderma pigmentosum and Cockayne syndrome lymphoblastoid lines has also been proven: the lines' viability ratio $^{831}$ have the same relative survival as do the colonyforming abilities of the patients' fibroblast lines. ${ }^{6732}$

\section{Results}

Post-X-ray survival. Dose-response curves were obtained for one ataxia telangiectasia line (fig 1A), two Parkinson's disease lines (fig 1B), two Alzheimer's disease lines (fig 1C), and three lines $\frac{0}{\sigma}$ from normal donors who were age-matched with the Parkinson's disease and Alzheimer's disease donor (fig 1A). The three normal lines had similar surviva $\vec{c}$ curves. The ataxia telangiectasia line had a marke $\mathbb{8}$ hypersensitivity to X-rays. Although the Parkinson' 8 disease and Alzheimer's disease lines were less sen sitive than the ataxia telangiectasia line to the lethe $\frac{\mathbb{Q}}{\mathrm{D}}$ effects of X-rays, the Parkinson's disease pair, $\vec{\varphi}$ well as the Alzheimer's disease pair, had lower sur- o vival at each of the doses tested than the normal lines $(p<0.05)$.

Additional experiments were performed, using a radiation dose of 100 rads, to compare the post-Xray survival of all the patient lines with that of all the normal lines (fig 2). The post-X-ray viability ratios $\varnothing$ of all 28 normal lines is shown in the first column. $\overrightarrow{\overrightarrow{0}}$ The mean viability ratio \pm standard error for the 3 five multiple sclerosis lines $(0.530 \pm 0.011)$ and that for the five amyotrophic lateral sclerosis lines $(0.542$ ? $\pm 0.025)$ did not differ significantly from the mean ratio of $0.537 \pm 0.009$ of the normal group (fig 2) $(p>0.40)$. The eight Parkinson's disease lines (seven sporadic, one familial) had a mean viability ratio of $0.465 \pm 0.010$. The familial Parkinson's dis- $\delta$ ease line (RB 4642) had a viability ratio of $0.43 \xi$ which is one of the lowest in the Parkinson's disease $\mathrm{O}$ group $(\Theta$, fig 2$)$. When the mean viability ratio of either all eight Parkinson's disease lines or the seven sporadic Parkinson's disease lines was compared to that of the normal group, each Parkinson's disease or group had a significantly lower post-X-ray survival N 


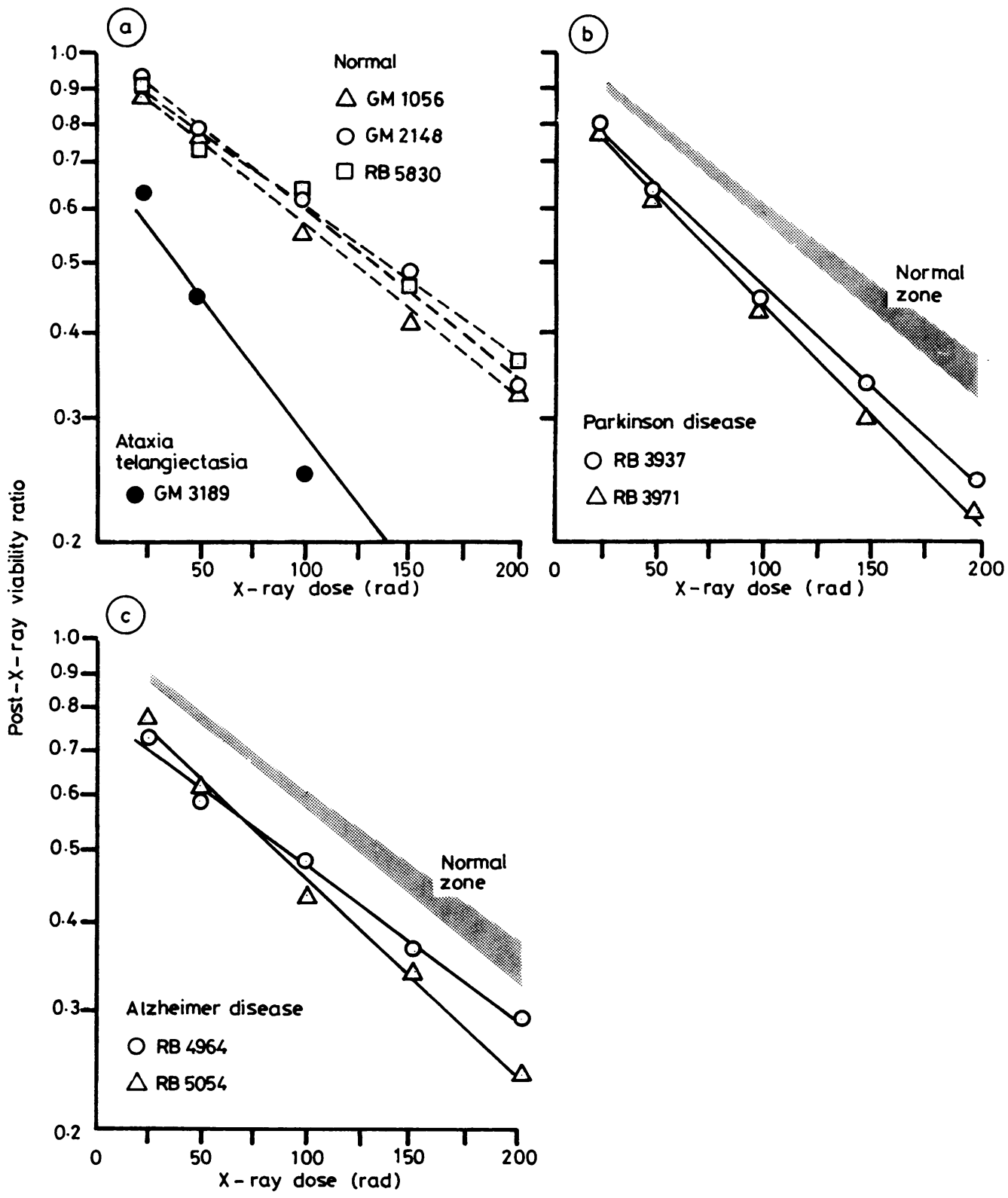

Fig 1 Dose-response survival curves for normal and representative patient lymphoblastoid lines after treatment with $X$-rays. (A) Normal cell lines and ataxia telangiectasia (AT) line. (B) Parkinson's disease lines. (C) Alzheimer's disease lines. The shaded "normal zone" of $\mathrm{B}$ and Cencompasses the survival curves of the three normal lines in A. The one male and two female normal donors were 65, 54, and 65 years of age, respectively. The age and sex of the Parkinson's disease and Alzheimer's disease donors are shown in tables 1 and 2, respectively. Each plotted data point for a cell line is the mean viability ratio obtained from six replicate experiments performed at the indicated $X$-ray dose. The exponential portion of each survival curve was not fitted to the plotted data points but was determined, as described previously, ${ }^{41}$ by averaging the slopes and intercepts calculated from the six replicate experiments performed on each line. Although the viability ratios of the ataxia telangiectasia disease line at the 150 and 200 rad doses are not shown, they were used in calculating the slope of the exponential portion of its survival curve. 


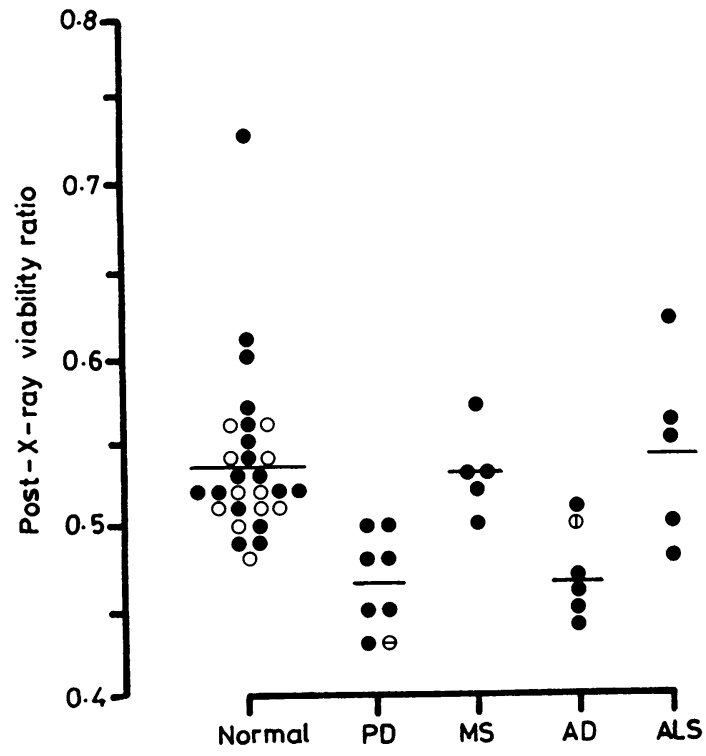

Fig 2 Survival of lymphoblastoid lines treated with 100 rads of $X$-rays. Each symbol represents the mean viability ratio of at least five replicate experiments on each normal and at least six replicate experiments on each patient line. A total of 280 experiments were performed on the normal, 65 on the Parkinson's disease (PD), 36 on the multiple sclerosis (MS), 53 on the Alzheimer's disease $(A D)$, and 31 on the amyotrophic lateral sclerosis $(A L S)$ lines. Each horizontal bar represents the mean ratio for its group. Omission of the highest normal line, whose viability ratio of 0.73 increases the variance of the normal group, would result in a mean ratio for the normal group of $0.530 \pm 0.006$ and in lower $\mathrm{p}$ values for the Parkinson's disease and Alzheimer's disease groups $(p \leqslant 0.0002)$. Open circles $=$ lines from the 11 oldest normal donors whose ages are similar to those of the Alzheimer's disease and Parkinson's disease patients; $\Theta=$ line from the patient with familial Parkinson's disease; $(D=$ line from the patient with familial Alzheimer's disease.

$(p=0.0004$ and 0.0001 , respectively). The six Alzheimer's disease lines (five sporadic, one familial) had a mean viability ratio of $0.472 \pm 0.011$. The familial Alzheimer's disease line (RB 4160) had a viability ratio of 0.50 which is near the top of the Alzheimer's disease group ( $\Phi$, fig 2$)$. When the mean viability ratio of either all six Alzheimer's disease lines or the five sporadic Alzheimer's disease lines was compared to that of the normal group, each Alzheimer's disease group had significantly lower post-X-ray survival $(p=0.004)$. The lines (open symbols) from the 11 oldest normal donors, whose mean age is similar to that of the Parkinson's disease and Alzheimer's disease donors, had a mean viability ratio of $0.523 \pm 0.008$ which was significantly different from that of either the Parkinson's disease or Alzheimer's disease group $(p \leqslant 0.002)$.

Post-ultraviolet irradiation survival. The eight normal lymphoblastoid lines studied had a mean postultraviolet irradiation viability ratio of $0.68 \pm 0.03$ (data not shown). The post-ultraviolet irradiation survival was determined for three Parkinson's disease lines (RB 3971, 3937, 5860) and three Alzheimer's disease lines (RB 4160, 5050, 5176) (data not shown). Their mean post-ultraviolet irradiation viability ratios were, respectively, $0.73 \pm$ 0.04 and $0.66 \pm 0.03$ and did not differ significantly from the mean post-ultraviolet irradiation viability ratio of the eight normal lines $(p>0 \cdot 30)$.

\section{Discussion}

Alzheimer's disease and Parkinson's disease are both progressive degenerations of the central nervous system occurring in the elderly.2433 Both Alzheimer's disease $2^{2633}$ and Parkinson's disease $^{243334}$ are sporadic disorders, although occasional cases of Alzheimer's disease manifesting autosomal-dominant inheritance have beeno reported. ${ }^{26}$ In Alzheimer's disease there is progres-ब्ठ sive loss of neurons in the cerebral cortex,${ }^{29}{ }^{33}$ basalo forebrain, ${ }^{35}$ and locus ceruleus. ${ }^{24}{ }^{36}$ In Parkinson' $s=0$ disease there is progressive loss of neurons in the substantia nigra, ${ }^{24}$ basal forebrain, ${ }^{37}$ and locuso ceruleus, ${ }^{2433}$ and some demented Parkinson's disease patients have neuropathological features whick are indistinguishable from those of Alzheimer's dis-ease. ${ }^{37}$ There has so far been no pathophysiological explanation for the neurodegeneration in either Parkinson's disease or Alzheimer's disease.

Recent studies have suggested that some disorders associated with a primary neuronal degeneration have hypersensitivity to DNA-damaging agents.' The first of these disorders to be so identified $^{38}$ was xeroderma pigmentosum, an autosomal recessive disease with inherited defects in the repair of the ultraviolet irradiation-type of DNAdamaging agent, ${ }^{2}$ resulting in severe actinic degeneration of sun-exposed skin. ${ }^{21}$ Some xeroderma pigmentosum patients develop a relentlessly progressive primary neuronal degeneration, usually in childhood, ${ }^{1-356}$ but occasionally as late as the fourth decade. ${ }^{4}$ Neuronal loss occurs in several sites, ${ }^{125}$ including some of those affected in Alzheimer's disease and/or Parkinson's disease, namely the locus ceruleus and substantia nigra. There is hypersensitivity to ionizing radiation and radiomimetic DNA-damaging chemicals in cells from patients with the primary neurodegenerations of ataxia telangiectasia, ${ }^{1214-19}$ Huntington's disease, ${ }^{12}$ 15 $1621-24$ 
Friedreich's ataxia, ${ }^{20}$ and familial dysautonomia. ${ }^{24}$ However, some primary neuronal degenerations may have no hypersensitivity to DNA-damaging agents. Thus, groups of fibroblast lines from patients with the motor neuron diseases spinal muscular atrophy and amyotrophic lateral sclerosis were not hypersensitive to a radiomimetic chemical ${ }^{34}$ while the groups of amyotrophic lateral sclerosis fibroblast $^{20}$ and lymphoblastoid (fig 2 ) lines studied had a normal sensitivity to ionizing radiation. These results with motor neuron disease lines do not rule out the possibility that an individual amyotrophic lateral sclerosis or spinal muscular atrophy line might be hypersensitive to these DNA-damaging agents $^{24}{ }^{34}$ or that motor neuron disease lines might be hypersensitive to some other type of DNAdamaging agent. However, spinal muscular atrophy and amyotrophic lateral sclerosis cells probably have no hypersensitivity to ultraviolet irradiation, since the patients' sun-exposed skin is not known to have clinical hypersensitivity to the ultraviolet irradiation in sunlight.

The specificity of the hypersensitivity of the radiosensitive neurodegenerations for the $X$ ray-type of DNA-damaging agent, as apposed to the ultraviolet irradiation type, has been well documented by the normal response to ultraviolet irradiation found in cultured cells from patients with ataxia telangiectasia, ${ }^{1}{ }^{12} 18$ Huntington's disease, ${ }^{12} 24$ Parkinson's disease and Alzheimer's disease (Results). Thus, the radiosensitivity is not due to an inability to respond normally to all types of DNAdamaging agent. Specificity of the radiosensitivity as a feature of certain primary neuronal degenerations, as opposed to many other diseases affecting the nervous system, is attested to by the failure to find hypersensitivity to the lethal effects of the Xray-type of DNA-damaging agent in cultured cells from patients with the following: (1) the demyelinating disorders multiple sclerosis ${ }^{40}$ (fig 2) and Cockayne syndrome; ${ }^{1213183140}(2)$ the primary neuronal degenerations xeroderma pigmentosum ${ }^{1} 12131825$ and motor neuron disease ${ }^{2034}$ (fig 2); and (3) a group of 16 lymphoblastoid lines from patients with ten genetic disorders with neurological involvement but without primary degeneration of excitable tissue. ${ }^{12}$ However, radiosensitivity has been found in cultured cells from patients with degeneration of certain nonneural excitable tissue, viz, skeletal muscle in the muscular dystrophies, ${ }^{41}$ including Duchenne muscular dystrophy, ${ }^{17} 25$ and photoreceptors in a primary pigmentary retinal degeneration, the autosomal recessive disorder Usher syndrome. ${ }^{17}$

The radiosensitivity in cultured nonneural cells from patients with Parkinson's disease and Alzheimer's disease is likely to result from a stable genetic defect, as indicated by the maintenance of the radiosensitivity in the patients' serially propagated cells in tissue culture. We therefore postulate that the abnormality resulting in radiosensitivity of our sporadic Parkinson's disease and Alzheimer's disease patients' cell lines and in the premature death of their neurons in vivo is the result of a dominant somatic mutation occurring during embryogenesis and not involving the patients' germ cells. Involvement of the patients' germ cells would lead to a familial form of the disease. Lymphoblastoid lines from patients with Duchenne muscular dystrophy, a disease known to be either inherited or acquired by a spontaneous mutation, ${ }^{42}$ are also hypersensitive to $\mathrm{X}$-rays. ${ }^{17} 25$

Because the age of onset of neurodegeneration in xeroderma pigmentosum correlates with the degree of hypersensitivity in vitro of the patients' fibroblast and lymphoblastoid lines to killing by ultraviolet irradiation, ${ }^{146-8}$ the premature death of xeroderma pigmentosum neurons may result from the accumulation of unrepaired damage in neuronal DNA. ${ }^{24674-11}$ Such damage would be caused by normally occurring DNA-damaging cellular metabolites, reactive oxygen species, and spontaneous hydrolytic reactions. ${ }^{143}$ Our DNA-damage hypothesis provides an explanation for the in vitro radiosensitivity and for the in vivo premature death of neurons in Parkinson's disease and Alzheimer's disease. Exposure of cells to X-rays in vitro results in many types of lesions in DNA. In normal cells a certain fraction of these potentially lethal lesions are unrepaired. In the Parkinson's disease and Alzheimer's disease patients' cells the fraction of these unrepaired lesions may be slightly higher due, perhaps, to the inability of the patients' cells to repair an infrequent type of normally repairable lesion. The resulting slight increase in number of lethal lesions remaining in the patients' cells could cause the hypersensitivity we have demonstrated. We postulate that there is defective repair of a type of potentially lethal lesion in the primary neuronal degenerations characterised by radiosensitivity. Since the DNA of neurons in vivo is constantly being damaged by spontaneous hydrolysis and intracellular metabolites, ${ }^{143}$ neuronal groups which undergo premature death would be those in which an unrepairable type of lesion represents a relatively large proportion of the potentially lethal lesions occurring. The different clinical and neuropathological patterns of these various disorders would result principally from different defective repair processes, from different mutations in the same repair process, or from different amounts of DNA damage. However, whatever the cause may be for the in vitro radiosensitivity we have described, the ability to 
study such an abnormality in cultured nonneural cells from Parkinson's disease and Alzheimer's disease patients may make it possible to elucidate the underlying mechanisms responsible for these diseases.

\section{References}

' Robbins JH. Hypersensitivity to DNA-damaging agents in primary degenerations of excitable tissue. In: Friedberg EC, Bridges BA, eds. Cellular Responses to DNA Damage. New York: Alan R. Liss, 1983:671700.

${ }^{2}$ Robbins JH, Kraemer KH, Lutzner ML, Festoff BW, Coon H. Xeroderma pigmentosum. An inherited disease with sun sensitivity, multiple cutaneous neoplasms, and abnormal DNA repair. Ann Intern Med 1974;80:221-48.

${ }^{3}$ De Sanctis C, Cacchione A. L'idiozia xerodermica. Rev Sper Freniatr 1932;56:269-74.

${ }^{4}$ Robbins JH, Polinsky RJ, Moshell AN. Evidence that lack of deoxyribonucleic acid repair causes death of neurons in xeroderma pigmentosum. Ann Neurol 1983;13:682-4.

5 Yano K. Xeroderma Pigmentosa mit Storungen des Zentralnervensystems: eine histopathologische Untersuchung. Folia Psychiat Neurol Jpn 1950;4:143-75.

- Andrews AD, Barrett SF, Robbins JH. Xeroderma pigmentosum neurological abnormalities correlate with colony-forming ability after ultraviolet radiation. Proc Natl Acad Sci USA 1978;75:1984-8.

7 Barrett SF, Tarone RE, Moshell AN, Ganges MB, Robbins JH. The post-UV colony-forming ability of normal fibroblast strains and of the xeroderma pigmentosum group G strain. J Invest Dermatol 1981;76:59-62.

${ }^{8}$ Moshell AN, Tarone RE, Newfield SA, Andrews AD, Robbins JH. A simple and rapid method for evaluating the survival of xeroderma pigmentosum lymphoid lines after irradiation with ultraviolet light. In Vitro 1981;17:299-307.

${ }^{4}$ Robbins JH. Guest editorial. The significance of repair of human DNA: evidence from studies of xeroderma pigmentosum. J Natl Cancer Inst 1978;61:645-56.

${ }^{10}$ Robbins JH. Workshop summary: xeroderma pigmentosum. In: Hanwalt PC, Friedberg EC, Fox CF, eds. DNA Repair Mechanisms. New York: Academic Press, 1978:603-7.

$"$ Robbins JH, Moshell AN. DNA repair processes protect human beings from premature solar skin damage: evidence from studies of xeroderma pigmentosum. $J$ Invest Dermatol 1979; 73:103-7.

12 Moshell AN, Tarone RE, Barrett SF, Robbins JH. Radiosensitivity in Huntington's disease: implications for pathogenesis and presymptomatic diagnosis. Lancet 1980;1:9-11.

${ }^{13}$ Robbins JH, Otsuka F, Tarone RE, et al. Radiosensitivity in Alzheimer disease and Parkinson disease. Lancet 1983;1:468-9.

14 Chen PC, Lavin MF, Kidson C, Moss D. Identification of ataxia telangiectasia heterozygotes, a cancer prone population. Nature 1978;274:484-6.

is Imray FP, Kidson C. Responses of Huntington's disease and ataxia telangiectasia lymphoblastoid cells to bleomycin. Chem Biol Interact 1983;47:325-36.

16 Paterson MC, Bech-Hansen NT, Blattner WA, Fraumeni Jr JF. Survey of human hereditary and只 familial disorders for $\gamma$-ray response in vitro: occur- $\frac{\rho}{\partial}$ rence of both cellular radiosensitivity and radioresistance in cancer-prone families. In: Nygaard OF, Simic $\overrightarrow{2}$ MG, eds. Radioprotectors and Anticarcinogens. New York: Academic Press, 1983:615-38.

${ }_{17}$ Robbins JH, Scudiero DA, Otsuka F, et al. Hypersensitivity to DNA-damaging agents in cultured $\frac{C}{\sigma}$ cells from patients with Usher's syndrome and $\overline{\bar{D}}$ Duchenne muscular atrophy. J Neurol Neurosurg $\underset{\oplus}{\overparen{D}}$ Psychiatry 1984;47:391-8.

18 Scudiero DA, Moshell AN, Scarpinato RG, et al. ڤ్ల Lymphoblastoid lines and skin fibroblasts from patients with tuberous sclerosis are abnormally sensi- ? tive to ionizing radiation and to a radiomimetic chemi- $\overrightarrow{\vec{\Delta}}$ cal. J Invest Dermatol 1982;78:234-8.

${ }^{14}$ Taylor AMR, Harnden DG, Arlett CF, et al. Ataxiatelangiectasia: a human mutation with abnormal radiation sensitivity. Nature 1975;258:427-9.

${ }^{20}$ Chamberlain S, Lewis PD. Studies of cellular hypersen- $\stackrel{\oplus}{\infty}$ sitivity to ionizing radiation in Friedreich's ataxia. $J$ Neurol Neurosurg Psychiatry 1982;45:1136-8. Tृ

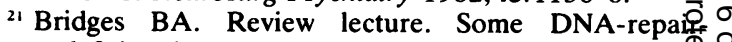
deficient human syndromes and their implications for human health. Proc $R$ Soc Lond B 1981;212:263-78. -

${ }^{22}$ Chen P, Kidson C, Imray FP. Huntington's diseasej: implications of associated cellular radiosensitivity. Clin Genet 1981;20:331-6.

${ }^{23}$ McGovern D, Webb T. Sensitivity to ionizing radiation of lymphocytes from Huntington's chorea patien

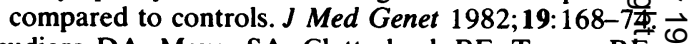

${ }^{24}$ Scudiero DA, Meyer SA, Clatterbuck BE, Tarone RE, Robbins JH. Hypersensitivity to $N$ - or methyl- $N^{\prime}$-nitro- $N$-nitrosoguanidine in fibroblasts $\square$ from patients with Huntington's disease, familial dysautonomia and other primary neuronal degenerations. Proc Natl Acad Sci USA 1981;78:6451-5.

${ }^{25}$ Tarone RE, Otsuka F, Robbins JH. A sensitive assay $\frac{2}{D}$ for detecting hypersensitivity to ionizing radiation in $\varrho$ lymphoblastoid lines from patients with Duchenne $\overrightarrow{\overline{0}}$ muscular dystrophy and primary neuronal degenerations. J Neurol Sci 1984;65:367-81.

${ }^{26}$ Nee LE, Polinsky RJ, Eldridge R, Weingartner $\mathbf{H}$, Smallberg S, Ebert M. Family with histologically confirmed Alzheimer's disease. Arch Neurol 1983;40:203-8.

${ }^{27}$ Rose AG, Ellison G, Myers L, Tourtellotte W. Criteria for the clinical diagnosis of multiple sclerosis. Neurology (Minneap) 1976;26:20-2.

${ }^{28}$ Armitage P. Statistical Methods in Medical Research. New York: John Wiley and Sons, 1971.

${ }^{24}$ Blackwood W, Corsellis JAN. Greenfield's Neuropathology, 3rd Ed. London: Edward Arnold, 1976.

${ }^{30}$ Sedgwick RP. Neurological abnormalities in ataxiatelangiectasia. In: Bridges BA, Harnden DG, eds. N Ataxia-Telangiectasia-a cellular and Molecular Link Between Cancer, Neuropathology, and Immune Defi- 옹 
ciency. New York: John Wiley and Sons, 1982:23-35.

${ }^{31}$ Otsuka F, Tarone RE, Cayeux S, Robbins JH. Use of lymphoblastoid cell lines to evaluate the hypersensitivity to ultraviolet radiation in Cockayne syndrome. $J$ Invest Dermatol 1984;82:480-4.

32 Andrews AD, Barrett SF, Yoder FW, Robbins JH. Cockayne's syndrome fibroblasts have increased sensitivity to ultraviolet light but normal rates of unscheduled DNA synthesis. J Invest Dermatol 1978;70:237.

${ }^{33}$ Adams RD, Victor M. Principles of Neurology, 2nd ed. New York: McGraw Hill, 1981:794-832.

${ }^{34} \mathrm{DuVoisin}$ RC. Is Parkinson's disease acquired or inherited? Can J Neurol Sci 1984;11:151-5.

${ }^{35}$ Whitehouse PJ, Price DL, Struble RG, Clark AW, Coyle JT, DeLong MR. Alzheimer's disease and senile dementia: loss of neurons in the basal forebrain. Science 1982; 215: 1237-9.

${ }^{36}$ Iversen LL, Rossor MN, Reynolds GP, et al. Loss of pigmented dopamine-hydroxylase positive cells from locus coeruleus in senile-dementia of Alzheimer's type. Neurosci Lett 1983;39:95-100.

${ }^{37}$ Whitehouse PH, Hedreen JC, White CL III, Price DL. Basal forebrain neurons in the dementia of Parkinson disease. Ann Neurol 1983;13:243-8.

${ }^{38}$ Cleaver JE. Defective repair replication of DNA in xeroderma pigmentosum. Nature 1968;218:652-6.

${ }^{34}$ Scudiero DA, Brumback RA, Tarone RE, Clatterbuck $\mathrm{BE}$, Robbins JH. Amyotrophic lateral sclerosis and spinal muscular atrophy fibroblasts are not hypersensitive to killing by a DNA-damaging agent. Clin Res 1983;31:292A.

${ }^{40}$ Scudiero DA, Brumback RA, Clatterbuck BE, Tarone RE, Robbins JH. Cells from patients with demyelinating diseases are not hypersensitive to $N$-methyl- $N^{\prime}$-nitro- $N$-nitrosoguanidine. Clin Res 1982;30:688A.

41 Tarone RE, Scudiero DA, Robbins JH. Statistical methods for in vitro cell survival assays. Mutat Res 1983;111:79-96.

42 Rowland LP, Layzer RB. X-linked muscular dystrophies. In: Vinken PJ, Bruyn GW, Ringe ISP, eds. Diseases of Muscle, Part I. Handbook of Clinical Neurology Vol. 40. Amsterdam: Elsevier-North Holland Biomedical Press, 1979:349-414.

${ }^{43}$ Setlow RB. DNA repair, aging, and cancer. In: Research Frontiers in Aging and Cancer: International Symposium for the 1980s. National Cancer Institute Monograph 60, NIH Publication No. 82-2436, 1982:249-55. 